\title{
THE IMPACT OF RENAL DISEASE IN LIVER TRANSPLANTATION
}

\section{Ana Carina Ferreira ${ }^{1}$, Fernando Nolasco ${ }^{1}$ : Sandra Sampaio ${ }^{1}$ : Alexandre Baptista ${ }^{1}$ : Pedro Pessegueiro ${ }^{1}$ : Estela Monteiro ${ }^{1}$ : Américo Martins ${ }^{1}$ : Eduardo Barroso ${ }^{1}$ \\ 1- Unidade de Transplante, Hospital de Curry Cabral}

\section{INTRODUCTION AND AIMS}

Orthotopic liver transplantation (OLT) has become the treatment of choice for advanced liver disease of almost any cause.

Improved outcomes among solid organ transplant recipients have contributed to the growth in the absolute number of patients with chronic kidney disease (CKD) in this group, and this complication significantly compromises patients outcome ${ }^{1-3}$.

The aim of this study was to determine the incidence of acute and chronic renal disease, possible risk factors and the impact on the patient survival.

\section{RESULTS}

708 OLT recipients:

- Male gender $64 \%$

- Mean age: $44 \pm 12.6$ years

- Diabetes in 106 patients (17\%); Hypertension in 117 patients (18.8\%)

- Mean follow up time 3.6 years, $29 \%>$ to 5 years

- Mean transplant survival: $75 \%$ at 12 months and $69 \%$ at 3 years

- RD pre (GFRe $<60 \mathrm{ml} / \mathrm{min}$ or $\mathrm{Scr}>1.5 \mathrm{mg} / \mathrm{dl}$ ): 133 recipients $(21.6 \%)$

- Retransplanted: 82 recipients

- Death: 152 recipients

\section{POPULATION AND METHODS}

This was a retrospective study of 626 patients receiving 708 OLT, transplanted in our unit between September 1992 and March 2007.

Clinical data: age at transplantation, gender, weight, aetiology for hepatic failure, presence of diabetes mellitus, hypertension, hepatitis B and C infection, renal dysfunction pre transplant (RD pre), immunosuppression (ISS) and necessity for acute renal replacement therapy (RRT).

Laboratorial data: serum creatinine (Scr) values and/or glomerular filtration rate (GFR), determined by Cockcroft-Gault equation, at the last observation pre transplantation and at days 1,7 and 21, month 6 and every year post transplantation.

\section{AKI}

$n=213(33.8 \%)$

GFRe $\leq 30 \%$ of pre transplant GFR

Scr $\geq 1.8 \mathrm{mg} / \mathrm{dl}$

RRT in $15.5 \%(n=34)$

Death in $30.5 \%(n=65)$

Indications for transplantation

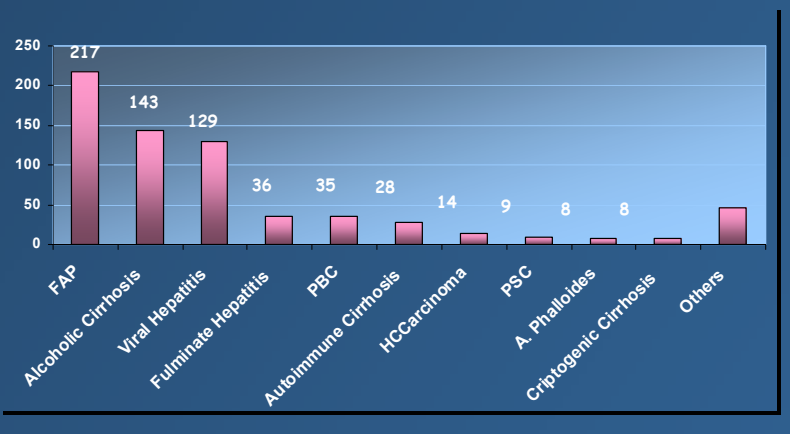

Renal recovery in $1.4 \%(n=3)$

\section{CKD} $n=355(50.2 \%)$

\begin{tabular}{|l|c|c|}
\multirow{2}{*}{ Spearman Correlation } & \multicolumn{2}{l}{} \\
\cline { 2 - 3 } & $\mathrm{r}$ & $\mathrm{p}$ \\
\hline Age & 0.19 & $<0.001$ \\
\hline Diabetes & 0.88 & 0.003 \\
\hline Alcoholic Cirrhosis & 0.09 & 0.015 \\
\hline RD pre & 0.28 & $<0.0001$ \\
\hline AKI post transplant & 0.32 & $<0.0001$ \\
\hline Mortality & 0.19 & $<0.0001$ \\
\hline
\end{tabular}

\begin{tabular}{|l|c|c|c|}
\cline { 2 - 3 } Linear Regression & Cl 95\% & $\mathbf{p}$ & $\mathbf{R}^{2}$ \\
\hline CKD stage 3 & 0.54 to 0.85 & 0.001 & \\
\hline CKD stage 5d & 0.03 to 0.3 & 0.02 & \multirow{2}{*}{0.47} \\
\hline Re transplantation & 0.003 to 0.17 & 0.04 & \\
\hline Mortality & 0.01 to 0.17 & 0.02 & \\
\hline
\end{tabular}

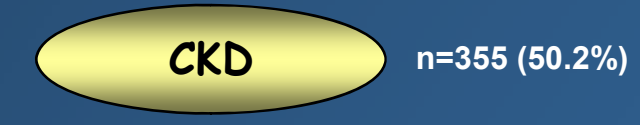

\begin{tabular}{|c|c|c|c|}
\hline & Cl 95\% & p & $\mathbf{R}^{2}$ \\
\hline Age & 1.02 to 1.06 & $<0.001$ & \multirow{4}{*}{0.19} \\
\hline RD pre & 0.24 to 0.66 & $<0.001$ & \\
\hline AKI post transplant & 0.37 to 0.95 & 0.03 & \\
\hline Mortality & 0.26 to 0.88 & 0.015 & \\
\hline
\end{tabular}

\section{MORTALITY}

\begin{tabular}{|l|c|c|c|}
\cline { 2 - 3 } \multicolumn{1}{l|}{ Linear Regression } & Cl $95 \%$ & $\mathbf{P}$ & $\mathbf{R}^{2}$ \\
\hline RD pre & $\mathbf{0 . 0 1}$ to 0.14 & $\mathbf{0 . 0 2}$ & \multirow{2}{*}{0.18} \\
\hline AKI post transplant & $\mathbf{0 . 0 6}$ to 0.26 & $<0.001$ & \multirow{2}{*}{$\mathbf{0 . 1 8}$} \\
\hline CKD stage 5d & 0.34 to 0.61 & $<0.001$ & \\
\hline
\end{tabular}

\section{CONCLUSIONS}

OLT are disposed to acute and chronic renal complications that have negative impact in the survival of these patients.

Renal dysfunction seems to be more important than the need of re transplant in what concerns clinical prognostic. 